\title{
Le Laboratoire de Farcha et les programmes d'éradication de la peste bovine au Tchad de 1949 à 2007 : une synthèse
}

\author{
Adam Hassane Deye ${ }^{1 *}$ Guillaume Duteurtre ${ }^{2}$ \\ Mahamat Ouagal $^{3}$
}

\section{Mots-clés}

Bovin, peste bovine, vaccin, élevage de bétail, laboratoire vétérinaire, Tchad

(C) A.H. Deye et al., 2021

\section{(c)}

https://creativecommons.org/licenses/by/4.0/

Accepted: 8 November 2021

Published: 20 December 2021

DOI: 10.19182/remvt.36816

\begin{abstract}
Résumé
Ce travail de synthèse présente le rôle de l'Institut de recherche en élevage pour le développement (IRED), anciennement Laboratoire de Farcha, dans la lutte contre la peste bovine au Tchad. Créé en 1949 par les autorités coloniales, ce laboratoire implanté à N'Djamena joue dès sa création un rôle déterminant dans les recherches sur la peste bovine en Afrique centrale. Dans la première période, ou « temps des vaccins » (1953-1961), les travaux du laboratoire conduisent notamment à la fabrication de plusieurs générations de vaccins. Dans la deuxième période, ou « temps des campagnes » (1962-1985), ces vaccins sont utilisés à grande échelle pour des programmes d'éradication de la maladie. Les vaccins en culture cellulaire produits à Farcha sont en particulier utilisés lors de la campagne lancée par l'Organisation de I'Unité africaine (1962-1976) sous le nom de Programme conjoint $n^{\circ} 15$. Ce programme aboutit à l'éradication temporaire de la peste bovine au Tchad. Malheureusement la persistance de foyers de la maladie dans plusieurs zones d'Afrique et l'arrêt des campagnes de vaccination au Tchad à la fin des années 1970 conduisent à son retour à partir de 1982. Suite au redémarrage de la production de vaccins en 1983 puis à la nationalisation du laboratoire en 1985, Farcha reste actif dans la lutte contre la peste bovine. Au cours de la troisième période, ou « temps de la surveillance » (1986-2007), le laboratoire contribue activement à la Campagne panafricaine contre la peste bovine (PARC), puis au Programme panafricain de contrôle des épizooties (PACE), notamment par des activités d'épidémiosurveillance et de sérosurveillance. Ces programmes conduisent à l'éradication définitive de la maladie dans la région. Depuis 2007, le Tchad est déclaré indemne de peste bovine, ce qui a contribué à l'augmentation rapide des effectifs bovins dans le pays et lui a ouvert des opportunités commerciales, surtout en matière d'exportation de bétail sur pied vers ses voisins.
\end{abstract}

- Comment citer cet article : Deye A.H., Duteurtre G., Ouagal M., 2021. Farcha Laboratory and rinderpest eradication programs in Chad from 1949 to 2007: a review. Rev. Elev. Med. Vet. Pays Trop., 74 (4): $213-$ 224, doi: $10.19182 /$ remvt.3681610.19182/remvt.36816

\section{Introduction}

$\mathrm{Au}$ Tchad, on estime que l'élevage représente $37 \%$ de la valeur totale de la production agricole, soit 14 à $20 \%$ du produit intérieur brut. Lélevage contribue aussi à la balance commerciale, puisque le bétail sur pied représente en valeur, hors pétrole, le premier poste des

\footnotetext{
1. Lycée francophone Goudji, Quartier Goudji, N'Djamena, Tchad. 2. CIRAD, UMR SELMET, F-34398 Montpellier, France.

SELMET, Univ Montpellier, CIRAD, INRAE, Institut Agro, Montpellier, France. 3. Institut de recherche en élevage pour le développement (IRED), N'Djamena, Tchad.

* Auteur pour la correspondance

Tél. : +235662482 26 ; email : hassadeye@yahoo.fr
}

exportations, juste avant le coton (PNDE, 2017). L'élevage mobilise par ailleurs $40 \%$ de la population active et fait vivre plus de $70 \%$ de la population rurale, leur procurant une source de revenus (PNDE, 2017). Enfin, l'élevage au Tchad, en plus d'être un secteur important de l'économie nationale, est ancré dans la culture et les traditions de nombreuses populations rurales.

Pour ces populations, la peste bovine a constitué pendant la plus grande partie du $\mathrm{XX}^{\mathrm{e}}$ siècle une entrave majeure au développement du cheptel bovin en raison du taux très élevé des mortalités qu'elle engendre dans un troupeau contaminé (encadré 1). Toutefois, à la suite des nombreux programmes de lutte conduits entre les années 1960 et 2000, le Tchad fut reconnu en 2007 indemne de peste bovine par l'Office international des épizooties (OIE). 
Créé en 1949 en tant qu'institution coloniale et nationalisé dans les années 1980,1'Institut de recherche en élevage pour le développement (IRED), anciennement Laboratoire de Farcha (figure 1), est un centre de recherche tchadien qui a joué dès sa création un rôle déterminant dans les recherches et la lutte contre la peste bovine en Afrique centrale. Quels ont été les principaux programmes mis en œuvre ? Quelle fut, en particulier, l'implication du Laboratoire de Farcha dans l'éradication ? Pour répondre à ces questions, cet article présente un historique de ce laboratoire, en particulier de ses activités de diagnostic et de lutte sanitaire. Ces éléments sont mis en perspective avec les programmes de lutte internationaux ayant conduit à l'éradication de la peste bovine. Cet historique s'appuie sur une revue bibliographique, notamment des articles publiés par des chercheurs tchadiens ou étrangers, des témoignages de plusieurs vétérinaires ayant travaillé sur le territoire du Tchad, et des rapports d'activités du laboratoire. Les

Encadré $1 / / /$ Box 1

\section{LA PESTE BOVINE /// RINDERPEST}

La peste bovine est une maladie qui fut internationalement combattue jusqu'à son éradication planétaire en 2011. L'Office international des épizooties, rebaptisé Organisation mondiale de la santé animale, définit la peste bovine " comme une maladie virale contagieuse qui touche essentiellement les bovins et les buffles. Elle est due à un virus de la famille des paramyxoviridés, du genre Morbillivirus. Chez de nombreuses espèces d'animaux sauvages et domestiques artiodactyles, y compris les ovins et les caprins, l'infection est à l'origine d'une maladie qui se traduit par des symptômes atténués, mais dans un troupeau de bovins ou de buffles sensibles, espèces les plus souvent atteintes, le taux de mortalité peut atteindre $100 \% »(\mathrm{OIE}, 2013)$.

En Afrique, la peste bovine a été signalée à la fin du XIXe siècle. Pour Leplae et al. (1925), I'arrivée de la peste bovine sur le continent africain serait due à du bétail importé d'Autriche vers l'Egypte en 1841. Pour Curson (1919), elle aurait pu être importée en Afrique par du bétail russe embarqué dans des ports de la mer Noire et transporté au Soudan lors de l'Expédition du Nil menée par les troupes britanniques en 1884-1885. Mais c'est plus probablement à partir du port de Massawa, conquis par l'armée italienne en 1885 lors de la $1^{\text {re }}$ campagne $d^{\prime}$ Abyssinie, que les autres pays d'Afrique furent contaminés, donnant lieu à une épizootie majeure sur le continent de 1888 à 1897 (Sunseri, 2018).

Sur le territoire du Tchad, des contaminations sont rapportées dès le début de $X X^{\top}$ siècle. Des épizooties plus tardives ont été signalées dans les années 1927, 1928 et 1934 dans les régions du Tchad, du Nord Cameroun et du Nigeria britannique. Des épizooties avaient aussi frappé le Niger et le Sénégal entre 1915 à 1917, puis de 1918 à 1922 (Gallais, 1979), et encore en 1955-1956 au Sénégal et en Mauritanie (Daumal, 1996).

En arabe tchadien, les éleveurs appellent la peste bovine Djéderi ou Ammassarine. Cette dernière dénomination fait allusion aux diarrhées provoquées par la maladie. Dans la tradition tchadienne, la peste bovine est présentée comme une maladie très dangereuse et contagieuse : aucun éleveur ne veut voir son bétail approcher une zone supposée touchée. C'est pourquoi, durant les épizooties, des éleveurs se déplacent d'une zone à l'autre afin d'échapper à la contagion. Ces déplacements sont d'ailleurs susceptibles de favoriser la propagation de la maladie.

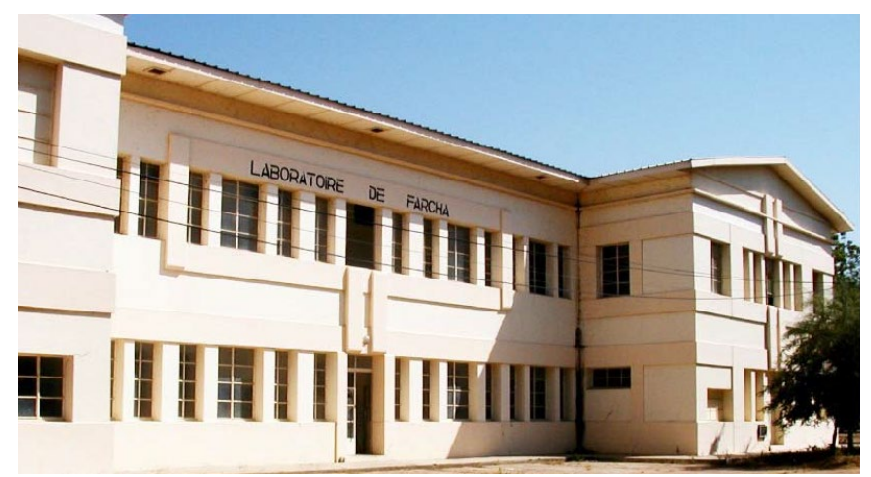

Figure 1 : Le Laboratoire de Farcha en 2006 /// Farcha Laboratory in 2006

rapports des campagnes de vaccination du Programme conjoint $n^{\circ} 15$ (PC 15) de la Campagne panafricaine contre la peste bovine (PARC) et du Programme panafricain de contrôle des épizooties (PACE) ont également été explorés.

La contribution du Laboratoire de Farcha aux programmes d'éradication de la peste bovine au Tchad s'articule autour de trois grandes périodes. Dans la première période (1949-1961) s’inscrivent les premiers programmes de lutte contre les foyers de peste bovine au Tchad. Dans la deuxième période (1962-1985) la campagne de vaccination panafricaine contre la peste bovine est conduite à travers le PC 15. Ce programme aboutit à une première éradication en 1979, suivie d'une période d'instabilité politique et du retour de la maladie dans le pays à partir de 1982. Dans la troisième période (1986-2007) le laboratoire redémarre sous un nouveau statut national, et les dernières campagnes de vaccination sont conduites avec les programmes PARC et PACE, jusqu'à l'éradication de la peste bovine au Tchad en 2007.

\section{Création du Laboratoire de Farcha et mise au point des premiers vaccins contre la peste bovine (1949-1961)}

\section{Naissance des services vétérinaires coloniaux}

L'implantation d'un laboratoire vétérinaire et zootechnique au Tchad procède de deux dynamiques concomitantes : un héritage colonial français et le soutien des autorités tchadiennes. Jusqu'aux années 1960, c'est la première dynamique qui prévaut. «L'histoire des vétérinaires tropicalistes est intimement liée aux conquêtes coloniales auxquelles les vétérinaires militaires attachés aux unités montées ont participé, d'abord pour s'occuper des animaux de transport (chevaux, dromadaires, bœufs porteurs) et du ravitaillement de la troupe. » (Daumal, 1996). Ces premiers vétérinaires tropicaux, accompagnant les troupes françaises qui pénètrent au Tchad à partir de 1891, étudient plusieurs maladies animales présentes en Afrique noire. Dupuy conduit des études sur les piroplasmoses équines, Pierre s’intéresse à la peste bovine et Monod à la péripneumonie contagieuse bovine (PPCB). Au Tchad, Pecaud travaille sur les trypanosomiases, puis rédige, de 1910 à 1917, plusieurs études sur les races domestiques tchadiennes (Daumal, 1996). Le Tchad est alors considéré comme un protectorat et garde ce statut jusqu'en 1920, date à laquelle il est érigé en colonie dans le cadre de l'Afrique équatoriale française (AEF).

Le Service de l'élevage du Tchad nait dans les années 1920 à l'initiative de la métropole. Le premier vétérinaire non militaire qui en est chargé est le Dr René Malbrant, en poste à partir de 1927. Il deviendra plus tard député de l'AEF représentant le Tchad et l'Oubangui-Chari. Pendant les années 1930, les vétérinaires français sont environ une trentaine. Le service d'élevage est alors une direction sous la tutelle du ministère français de l'Agriculture puis du ministère des Colonies. 
C'est dans ce cadre que sont créés au Tchad plusieurs centres de diagnostic vétérinaire et de recherche zootechnique : le Haras de Ngouri (province du Lac), le Centre de recherche zootechnique de Fianga (Mayo-Kebbi), le Centre expérimental de Ouadi-Rimé (Batha), le Centre d'Abou Goudam (Abéché), la Ferme de Bekamba (Mandoul), le Ranch de Bachoum et le Centre de Koukaya (dans le Hadjer-Lamis), et le Centre de Gaoui (Chari-Baguirmi). Répartis sur une grande partie du territoire, ces centres avaient pour mission de contribuer à améliorer les paramètres zootechniques des différentes espèces animales. A partir de 1933 entrent en fonction les deux centres vaccinogènes de Fort-Lamy (actuelle N'Djamena) et d'Abéché qui permettent de lancer les premières campagnes de vaccination (OIE, 1972).

Les grandes épizooties affectant l'élevage bovin tchadien sont alors la peste bovine, la PPCB, le charbon bactéridien, le charbon symptomatique et la pasteurellose (PNDE, 2017). La peste bovine, en particulier, est vécue par les éleveurs comme un véritable fléau. « Jusqu'en 1933, le Service de l'élevage s'est trouvé désarmé devant cette terrible maladie, hantise des éleveurs. On signale une épizootie ayant fait 200000 morts. A cette date, le premier centre vaccinogène fut créé mais les possibilités d'intervention, de par le nombre de doses produites, se trouvaient limitées autour des foyers pour empêcher la maladie de s'étendre » (Alfaroukh, 1989).

\section{Fondation du laboratoire}

Les pressions sanitaires persistantes et les défis rencontrés par les services de l'élevage au Tchad et dans la région nécessitent alors de créer sur place un centre de recherche, de diagnostic et de production de vaccins. «Pour une meilleure organisation, notamment de la lutte contre les maladies infectieuses les plus contraignantes pour la production animale, il s'est avéré nécessaire de mettre en place une structure de coordination au niveau régional. C'est ainsi que fut créé, à l'initiative de la direction de l'élevage, le Laboratoire de Farcha en 1949 dont la gestion scientifique et administrative fut confiée à l'Institut d'élevage et de médecine vétérinaire des pays tropicaux (IEMVT) », situé à Maisons-Alfort, France (PNDE, 2017).

La création du Laboratoire de Farcha est inscrite dans le premier plan du Fonds d'investissement pour le développement économique et social (FIDES), organisme français créé par la loi du 30 avril 1946, et dont la mission est d'encourager le développement économique et social des territoires d'outre-mer de l'Union française. L'installation de ce centre au Tchad a pour objectif l'amélioration de la production animale afin de permettre au pays de générer des revenus supplémentaires, en dehors de la culture du coton qui était alors la principale source de revenus du territoire. Le Tchad est aussi pensé comme pouvant jouer un rôle central dans l'approvisionnement en viande de la sous-région et de la Métropole.

Le chantier du laboratoire débute en 1949. Un emplacement lui est dédié à Farcha, quartier du premier arrondissement de Fort-Lamy, la capitale, sur la rive droite du fleuve Chari. Il s'agit de l'un des trois centres de recherches vétérinaires et zootechniques installés à cette époque dans les pays francophones d'Afrique, en plus de ceux de Dakar (Sénégal) et de Tananarive (Madagascar). Ces trois laboratoires dépendent de l'IEMVT qui, en plus de ses activités de recherche et de documentation, est un centre d'enseignement pour tous les jeunes docteurs vétérinaires qui désirent se spécialiser en médecine vétérinaire tropicale.

C'est Pierre Receveur, directeur de l'Elevage du Tchad dans les années qui suivent la Deuxième Guerre mondiale, qui soutient l'idée d'installer un tel centre à Fort-Lamy. «C'est toujours lui, ensuite, qui conçoit les plans d'un ensemble de bâtiments [...] et prend contact avec un architecte à Brazzaville [...]. C'est encore Pierre Receveur qui a l'idée géniale de ceindre les deux bâtiments principaux d'un immense couloir. Dans ce pays où la température monte aisément à $45^{\circ} \mathrm{C}$ et où l'électricité est très couteuse, ce grand couloir joue le rôle de tampon thermique bien avant l'arrivée de la climatisation » (Daumal, 1996). D'autres vétérinaires se joignent au projet de création du laboratoire, notamment Maurice Thomé, vétérinaire colonial en poste à l'est du Tchad dans la ville d'Abéché. Thomé est nommé directeur du Laboratoire de Farcha en 1952 et occupera ce poste jusqu'en 1965. Le premier bâtiment achevé (en 1953) du laboratoire est celui de la microbiologie. La construction se poursuivra jusqu'en 1955 avec les bâtiments destinés à la direction, à l'administration, à la bibliothèque, à la parasitologie, à l'agrostologie et à l'entomologie.

\section{Premières années orientées vers la formation et la santé animale}

Dans ses premières années, le Laboratoire de Farcha éprouve des difficultés liées au manque de moyens. Le Fides finance la construction du laboratoire mais le budget de fonctionnement incombe au territoire du Tchad. Les activités du laboratoire restent ainsi, en quelque sorte, limitées. Face à cette situation, les premiers chercheurs en poste se concentrent sur la formation. Ils décident d'envoyer des jeunes agents pour se former en médecine vétérinaire à l'IEMVT, et à l'Institut Pasteur de Paris.

Les missions du laboratoire sont orientées sur les recherches scientifiques et techniques nécessaires à la conservation, au développement et à l'amélioration du cheptel national ainsi qu'à la valorisation de ses sous-produits. Il a aussi pour mission la production de vaccins, sérums et autres produits biologiques nécessaires au maintien du cheptel en bon état sanitaire, ainsi que l'examen et l'analyse des prélèvements divers aux fins de poser les diagnostics.

Au-delà du Tchad, le Laboratoire de Farcha a une vocation régionale : il intervient dans certains pays voisins en vue d'entreprendre et de poursuivre des recherches, enquêtes et études pour appuyer le développement de l'élevage et l'exploitation des produits animaux. Le laboratoire appuie également l'Ecole nationale des infirmiers vétérinaires (ENIV) de Farcha, créée en 1946, qui deviendra en 1975 l'Ecole nationale de techniques d'élevage (ENATE), notamment en accueillant les étudiants en stage. Même si les missions du laboratoire sont larges, les travaux d'amélioration de la santé animale dominent en nombre et en importance.

\section{Organisation sous la tutelle de l'IEMVT}

Dans les années qui suivent sa création, le Laboratoire de Farcha est organisé administrativement en divisions et en services. La division de pathologie animale comprend les services de production de vaccins bactériens, de vaccins viraux, de diagnostics et recherches bactériologiques, de diagnostics et recherches virologiques, de diagnostics et recherches parasitologiques. Plus tard seront créés les deux services distincts d'épidémiologie et de biochimie appliquée. Le laboratoire compte aussi une division de production animale qui regroupe notamment les services de zootechnie-nutrition et d'agrostologie.

Le laboratoire est alors dirigé par l'IEMVT qui affecte un directeur résidant à Fort-Lamy. De sa création jusqu'à l'année de sa nationalisation en 1985, les directeurs du laboratoire sont des agents français de l'IEMVT, tous docteurs vétérinaires. De 1949 à 1960, le personnel tchadien du laboratoire passe de 67 à 108 personnes. Il se compose de techniciens, de personnels administratifs, d'ouvriers et de manœuvres. Dans la même période, le personnel européen passe de 6 à 30 personnes. Il est constitué de chercheurs, de techniciens et de personnels administratifs. Le laboratoire accueille aussi à cette époque en stage de nombreux étudiants (LRVZ, 1990).

\section{Foyers de peste bovine et premiers moyens de lutte périfocale}

Entre 1940 et 1950, les services vétérinaires identifient environ 400 foyers de peste bovine sur le territoire du Tchad. La stratégie de vaccination périfocale permet en théorie de circonscrire ces foyers. On utilise alors le vaccin formolé (ou vaccin poto-poto), qui reste en usage jusqu'au début des années 1950 (encadré 2). 
Encadré 2 /// Box 2

UTILISATION DU VACCIN FORMOLÉ CONTRE LA PESTE BOVINE À OUM HADJER EN 1954 ///

USE OF FORMALIN VACCINE AGAINST RINDERPEST IN OUM HADJER IN 1954

«Pour rejoindre Oum-Hadjer, Libeau mit à ma disposition son véhicule de tournée et son chauffeur. En cours de route, je rencontrai de nombreux éleveurs qui s'apprêtaient à partir en transhumance. Prévenus de mon passage, ils amenaient leurs troupeaux à vacciner contre la peste. L'ancien vaccin antibovipestique était encore seul en usage. A base de pulpe formolée de nœuds lymphatiques de veaux inoculés avec le virus, le vaccin poto-poto, bien que dépourvu d'un pouvoir protecteur de longue durée, était apprécié de ces éleveurs, si bien que nous passâmes, mes infirmiers et moi-même, quelques jours, dans la chaleur et la poussière, à vacciner plusieurs centaines de zébus » (Itard, 2012).

Le vaccin formolé est alors légèrement amélioré : «Quelques progrès sont réalisés vers 1950 par adjonction d'alumine au vaccin formolé, ce qui augmente la capacité de production. » (Alfaroukh, 1989). Ce vaccin formolé aluminé sera utilisé de 1951 à 1954 et produit dans les centres vaccinogènes de Fort-Lamy et d'Abéché (OIE, 1972).

Mais la couverture sanitaire du cheptel n'est pas satisfaisante et le nombre de foyers augmente (Vindrinet, 1991). D'une part, le vaccin formolé s'avère difficile à produire en grande quantité, et confère une immunité à la fois insuffisante et temporaire (Sacquet et Troquereau, 1952). D'autre part, les programmes de lutte s'avèrent complexes. Une des difficultés rencontrées pour les mettre en place réside dans l'impossibilité de mettre en œuvre l'abattage du bétail contaminé pour des raisons sociologiques, techniques et économiques (absence d'indemnités d'abattage) (Vindrinet, 1991). En 1951, la situation sanitaire est très mauvaise avec 698 foyers enregistrés et 21979 cas de maladie (figure 2).

\section{Production locale de vaccins lyophilisés et élargissement de la lutte}

A partir de 1953, la production locale de nouveaux types de vaccins permet cependant d'améliorer la stratégie de lutte contre la peste bovine. Le premier de ces nouveaux vaccins produits à Farcha est le vaccin capripestique. Il s'agit d'un vaccin vivant atténué produit sur chèvres inoculées, déjà testé à l'est du Tchad en 1949-1950 au centre vaccinogène d'Abéché (Sacquet et Troquereau, 1952). A cette époque, le vaccin n'est pas lyophilisé et il est conditionné en phase liquide. « C'est à partir de ce moment que sont entreprises des campagnes systématiques de vaccinations des jeunes. Ces campagnes sont rendues possibles par l'utilisation d'un vaccin capripestique dit humide à partir de 1953 »(Alfaroukh, 1989). En l'absence de matériel de lyophilisation, il est alors possible, à l'aide d'un simple réfrigérateur à pétrole, de conserver le virus au moins 60 jours (encadré 3).

Suite aux premières vaccinations capripestiques, le nombre de foyers baisse sensiblement (figure 2). Mais les mortalités postvaccinales
Encadré 3 /// Box 3

\section{UTILISATION DU VACCIN CAPRIPESTIQUE CONTRE LA PESTE BOVINE À MOUSSORO EN 1954 /// \\ USE OF CAPRIPESTIC (GOAT PLAGUE) VACCINE AGAINST RINDERPEST IN MOUSSORO IN 1954}

" [A Moussoro] nous disposions du réfrigérateur à pétrole des Leclercq, où je conservais, dans le tiroir à congélation [...] les rates de chèvres inoculées avec le virus bovipestique que m'envoyait Farcha. Le vaccin poto-poto venait d'être supplanté par le vaccin " capripestique », produit sur chèvres inoculées avec un variant peu pathogène du virus bovipestique. Les rates renfermant ce virus atténué étaient, après broyage, injectées à des chèvres saines que j'achetais une fois par mois au marché local. [...] Quand nous étions arrivés au campement des éleveurs, celles-ci étaient sacrifiées à l'acmé de leur température corporelle. Comme nous n'avions pas de thermomètres médicaux, la température s'évaluait au toucher. Le sang et la rate étaient, après broyage, injectés aux zébus de l'endroit. La plupart des éleveurs Kanembou appréciaient ce vaccin qui conférait à leurs animaux une immunité solide. Mais quelques-uns étaient méfiants et fuyaient notre approche avec leurs troupeaux» (Itard, 2012).

sont encore très élevées, le vaccin atténué gardant une virulence assez importante. Alors que les rapports officiels de l'époque indiquent des mortalités postvaccinales de $2 \%$, Provost et al. (1961) estiment qu'elles sont plutôt de l'ordre de $20 \%$ des primovaccinés.

Deux améliorations techniques majeures vont alors permettre de faire émerger de nouvelles générations de vaccins : la lyophilisation et l'utilisation des œufs embryonnés comme alternative à la chèvre pour la production de virus atténués. La production des premiers vaccins sous forme lyophilisée à Farcha est permise par l'acquisition de nouveaux matériels. En 1955, l'aide américaine permet l'achat d'un lyophilisateur Stokes, d'un appareil Cryochen, de machines destinées au remplissage et au scellement des ampoules, et d'un broyeur Eppenbach. Tout ce matériel permet la production, entre 1956 et 1960, de 23 gammes de vaccins contre diverses maladies telles que le charbon symptomatique, le charbon bactéridien, la pasteurellose bovine, la PPCB, la dermatophilose bovine et la peste bovine (rapports annuels 1956-1960). Les vaccins sont produits à partir de souches déjà disponibles, maintenues par passage sur des animaux locaux, notamment des veaux, des lapins et des chèvres.

Le vaccin antibovipestique lapinisé est plus atténué que le vaccin capripestique (Mornet et al., 1953), mais il s'avère beaucoup plus fragile et difficile à produire à Farcha en raison des difficultés rencontrées par l'élevage de lapins en zone sahélienne (Provost, 1961). Par ailleurs, le vaccin formolé est amélioré à partir de 1955 par l'utilisation de la saponine. Toutefois, la production de ce vaccin formolé saponiné est « rendue difficile par le trop petit nombre de veaux réagissant à l'inoculation virulente et dont l'immunité qu'il conférait ne remplissait

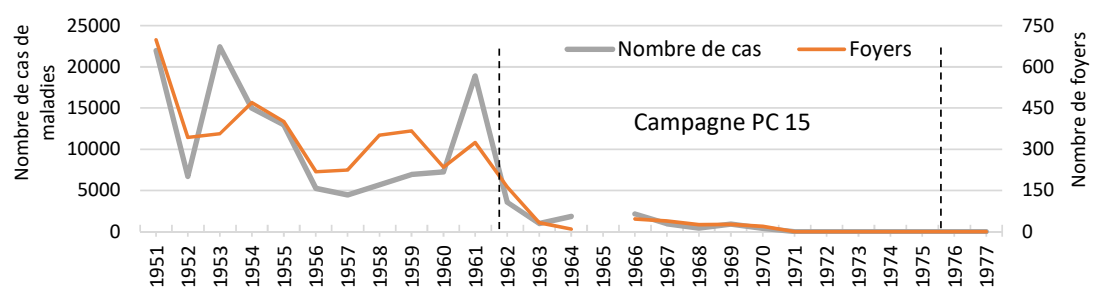

Figure 2 : Situation sanitaire de la peste bovine au Tchad entre 1951 et 1978 (NB : le « silence épidémiologique » de 1965). Source : données issues de Vindrinet (1991) /// Rinderpest situation in Chad between 1951 and 1978 (note the 'epidemiological silence' of 1965). Source: based on data from Vindrinet (1991) 
pas les conditions acceptables d'une politique de vaccination visant à l'éradication de la maladie » (Provost et al., 1961). Il reste utilisé uniquement dans les postes les plus isolés ne disposant pas d'équipements de réfrigération (Tacher, 2011).

Il convient alors de remplacer les vaccins formolé, capripestique et lapinisé par un autre vaccin de valeur antigénique comparable mais plus atténué. A partir de 1957, le laboratoire met au point un vaccin pestique avianisé, c'est-à-dire produit par passage sur œuf embryonné, technique déjà utilisée par d'autres laboratoires. Ce nouveau vaccin utilise la souche virale BA importée du Kenya en mars 1957 (Provost et al., 1961). Il sera d'une grande utilité pour faire face à une épizootie de peste bovine au Nord Cameroun en 1960. «La peste n'ayant pas sévi en Adamaoua depuis 1927, on avait affaire à une population bovine intégralement réceptive, et se posait alors la question du vaccin à employer pour renforcer les mesures sanitaires mises en place pour la protection. Le vaccin formolé est écarté par suite de ses difficultés de production et de la lenteur connue d'apparition de l'immunité. Restait le choix entre le capripestique et le vaccin avianisé souche BA que pouvait fournir le Laboratoire de Farcha » (IEMVT, 1960). Grâce à ce vaccin, une campagne d'éradication complète de la peste bovine est conduite en Adamaoua. Après cette épizootie au Nord Cameroun, les activités du laboratoire s'intensifient au début des années 1960 avec la réapparition de la peste bovine au Tchad et dans la sous-région de l'Afrique centrale.

La figure 3 résume la succession d'innovations vaccinales auxquelles le Laboratoire de Farcha a contribué. Elle mentionne en particulier les vaccins formolés, puis les vaccins lyophilisés capripestiques et avianisés. Les innovations ultérieures à 1961 sont abordées dans la section suivante.

\section{Activités de recherche et de mise au point de méthodes de diagnostic}

La peste bovine occupe également une place importante parmi les activités de recherche conduites à Farcha dans les premières années suivant sa création. Les équipes du laboratoire mettent ainsi en place une première méthode de diagnostic de la peste bovine dès 1955 et en développent ensuite plusieurs autres. L'enjeu consiste alors à mettre au point une technique de diagnostic spécifique permettant de différencier la peste bovine des autres maladies cliniquement semblables, notamment de la PPR (IEMVT, 1958 ; Bidjeh et al., 1995). Au début des années 1960 sont ensuite entrepris des travaux qui permettent la mise en évidence d'anticorps antibovipestiques chez des bovins convalescents et le développement de méthodes devant permettre à terme de détecter les animaux porteurs d'anticorps pestiques vaccinaux (IEMVT, 1960). Toutefois, au début des années 1960 deux événements majeurs vont profondément modifier l'environnement et les activités du laboratoire : l'accession du Tchad à l'indépendance en août 1960 et le lancement d'un programme panafricain de vaccination contre la peste bovine en 1962.

\section{Campagnes de vaccination et première éradication temporaire de la peste bovine (1962-1985)}

Suite à l'indépendance, la question du statut des centres de recherche est posée. En 1962, soit deux ans après l'indépendance du pays, le choix est fait de conserver le laboratoire sous la tutelle de son institution mère, l'IEMVT. Une convention est signée entre la République du Tchad et l'institut afin d'assurer le fonctionnement du Laboratoire de Farcha. Cette convention restera en vigueur pendant 25 ans, jusqu'à la rétrocession du laboratoire aux autorités tchadiennes en 1985. Pendant cette vingtaine d'années, il fournit 40,5 millions de doses de vaccin contre la peste bovine pour les campagnes de vaccination (Delate, 1985 ; Alfaroukh, 1989).

\section{Organisation et fonctionnement : un laboratoire national à vocation régionale}

Au terme du mandat de Maurice Thomé en 1965, Michel Graber lui succède à la direction du laboratoire (1965-1969), puis Alain Provost

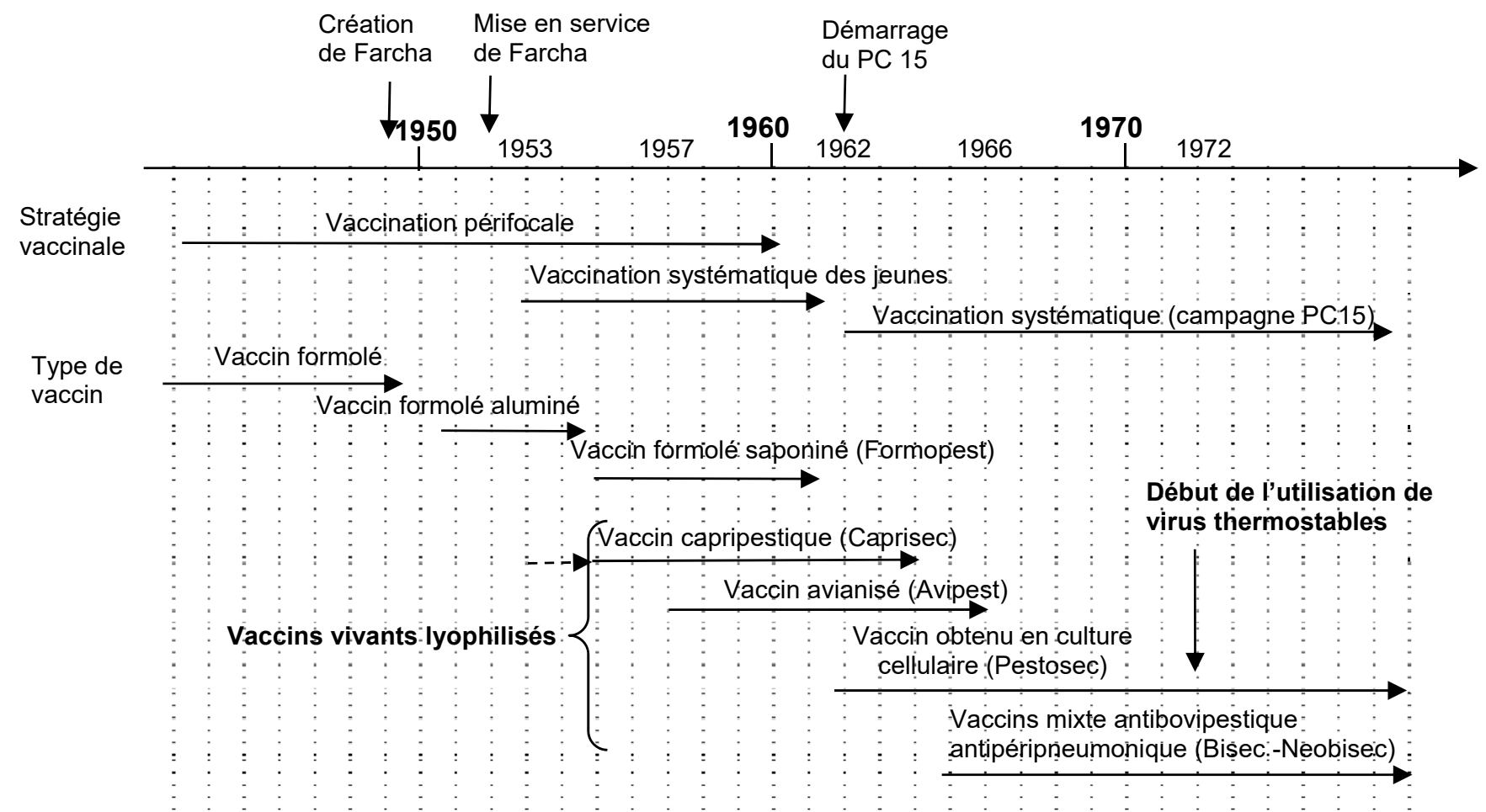

Figure 3 : Stratégies vaccinales au Tchad de 1945 à 1978. NB : la figure ne mentionne pas le vaccin lapinisé (Lapisec) produit uniquement de 1963 à 1964 et peu utilisé. Source : d'après Provost et al. (1961), OIE (1972), Vindrinet (1991), Libeau et al. (2011) /// Vaccine strategies in Chad from 1945 to 1978. Note the figure does not include the rabbit vaccine (Lapisec) produced only from 1963 to 1964 and little used. Source: adapted from Provost et al. (1961), OIE (1972), Vindrinet (1991), Libeau et al. (2011) 
(1969-1976) et Yves Cheneau (1976-1980). Devenu centre national, le laboratoire voit son organigramme légèrement modifié. La direction est transformée en direction générale appuyée d'un conseil d'administration. De 1963 à 1975, l'effectif du laboratoire augmente nettement, ce qui s'explique par l'intensification de la production de vaccins pour les campagnes conjointes antipestiques interafricaines. Les premiers scientifiques tchadiens sont recrutés au Laboratoire de Farcha entre 1974 et 1977 : il s'agit, par ordre d'arrivée, du Dr Nokouri Goukouni, microbiologiste, formé à l'Ecole vétérinaire de Maisons-Alfort, du Dr Djoudi Ozané, parasitologue, diplômé de l'Ecole vétérinaire de Bruxelles et spécialisé à Maisons-Alfort, puis de Brahim Boye, biochimiste diplômé de l'Université de Kharkov (H. Guerin et Y. Mopaté Logténé, commun. pers.). De 1962 à 1976, c'est au total 183 chercheurs européens (français essentiellement) qui auront travaillé au Laboratoire de Farcha, et autour de 1800 travailleurs tchadiens qui y seront passés. Ces effectifs rendent compte du rayonnement de cette institution.

\section{Mise au point de vaccins antibovipestiques en culture cellulaire}

Au début des années 1960, les programmes de lutte contre la peste bovine en Afrique centrale se heurtent au manque d'efficacité des vaccins capripestiques et avianisés. Le Laboratoire de Farcha est alors sollicité pour mettre au point un vaccin alternatif plus efficace. Cette demande est d'autant plus pressante que doit se lancer en 1962 une campagne internationale d'envergure.

En plus de la lyophilisation introduite en 1962, une nouvelle solution tampon à base de peptones est adoptée. Cette solution permet de multiplier les rendements en lyophilisation pour le vaccin capripestique (Caprisec) et pour le vaccin avianisé (Avipest). A la demande du Cameroun, du Tchad et de la République centrafricaine (RCA), le vaccin capripestique est produit en 1962 à hauteur de 3242600 doses, en remplacement du Formopest qui n'est plus produit qu'à hauteur de 6860 doses (IEMVT, 1962). Or, comme il l'a été signalé précédemment, le taux de mortalités postvaccinales induit par le vaccin capripestique s'avère plus élevé que prévu (Provost et al., 1961).

Dans ce contexte, c'est la mise au point de vaccins obtenus en culture cellulaire qui va constituer l'innovation majeure du début de ces années 1960 (figure 2). Au cours d'une expérience pilote réalisée à Farcha en 1960, les chercheurs montrent que le vaccin préparé avec la souche RBOK de Plowright et Ferris, multipliée sur culture cellulaire, immunise correctement les zébus, qui n'avaient jamais jusqu'ici été vaccinés avec ce type de vaccin (Provost, 1961). Ces recherches vont donner naissance au vaccin Pestosec qui sera fabriqué à partir de 1963. La confiance dans ce vaccin permet de généraliser sa production à d'autres laboratoires en Afrique, au Moyen-Orient et en Asie pour lutter contre cette maladie.

L'année 1963 marque le record dans la production de vaccins antibovipestiques depuis la création du laboratoire. Cette année-là, il produit près de sept millions de doses de vaccin capripestique. Le Pestosec est commercialisé mais en quantités encore très faibles car il vient d'être mis au point. Les livraisons des différents vaccins sont faites essentiellement au Tchad et au Cameroun, et de manière plus anecdotique au Mali, en RCA et en Côte d'Ivoire (tableau I).
Tableau I : Nombre de doses et pays de destination des vaccins antibovipestiques produits par le Laboratoire de Farcha (Tchad) en 1963 III Number of doses and countries of destination of the antibovine vaccines produced by Farcha Laboratory (Chad) in 1963

\begin{tabular}{lrrr} 
& Caprisec & Pestosec & Lapisec \\
\hline Nb. de doses & 6987240 & 194200 & 52900 \\
Dont livraison : & 4378140 & 27000 & 700 \\
au Tchad & & & \\
au Cameroun & 1063000 & 102000 & 11000 \\
au Mali & 80200 & 65200 & 15000 \\
en République centrafricaine & 9020 & & \\
en Côte d'Ivoire & 160 & & \\
\hline
\end{tabular}

Source : IEMVT, 1963

\section{Campagne de vaccination panafricaine du Programme conjoint (1962-1976)}

Le PC 15 contre la peste bovine est lancé en 1962 à l'initiative de plusieurs partenaires nationaux et internationaux, et grâce à l'aide de plusieurs bailleurs de fonds comme le Fonds européen de développement (FED), l'Agence des Etats-Unis pour le développement international (USAID), et les gouvernements du Canada, de l'Allemagne et du Royaume-Uni. La campagne conjointe est coordonnée par le Bureau interafricain pour les ressources animales de l'Organisation de l'Unité africaine (OUA-BIRA, actuel UA-IBAR). L'objectif visé à travers le PC 15 est de vacciner tous les bovins de tous âges, chaque année pendant trois années successives, en utilisant des vaccins vivants atténués permettant de conférer une immunité durable. De 1962 à 1976, le PC 15 est conduit en six phases dans 22 pays d'Afrique de l'Ouest, de l'Est et centrale. Il permet la vaccination de plus de 120 millions de têtes de bétail, pour un coût de 51 millions de dollars. Ses résultats aboutissent à une réduction sensible de l'incidence de la peste bovine mais sans parvenir à éradiquer définitivement la maladie sur le continent. Au terme de la campagne, la maladie refait surface en raison de foyers résiduels au Mali et en Ethiopie, les programmes de vaccination n'ayant pas été partout conduits avec la même rigueur.

Du fait de la campagne conjointe, le Tchad rend obligatoire la vaccination contre la peste bovine sur tout son territoire (Gouvernement du Tchad, 1960). Par ailleurs, il est institué un contrôle sanitaire de la circulation du bétail destiné aussi bien au commerce intérieur du Tchad qu'à l'exportation (Gouvernement du Tchad, 1962).

Le Laboratoire de Farcha est mis à contribution pour le PC 15. Il joue un rôle majeur dans la production de vaccins. Les autres laboratoires désignés pour cette production sont ceux de Dakar (Sénégal), Vom (Nigeria), Bamako (Mali), Debre Zeit (Ethiopie) et Muguga (Kenya). Au Tchad, entre 1 et 3 millions de têtes de bovins sont vaccinées chaque année entre 1962 et 1977 grâce aux vaccins produits à Farcha (figure 4).

\section{Mise au point de vaccins bivalents et thermostables}

$\mathrm{Au}$ début du programme PC 15, la production des vaccins capripestiques et avianisés diminue progressivement au profit du Pestosec. A
Figure 4 : Nombre de vaccinations contre la peste bovine effectuées au Tchad de 1951 à 1985 /// Number of vaccinations against rinderpest carried out in Chad from 1951 to 1985

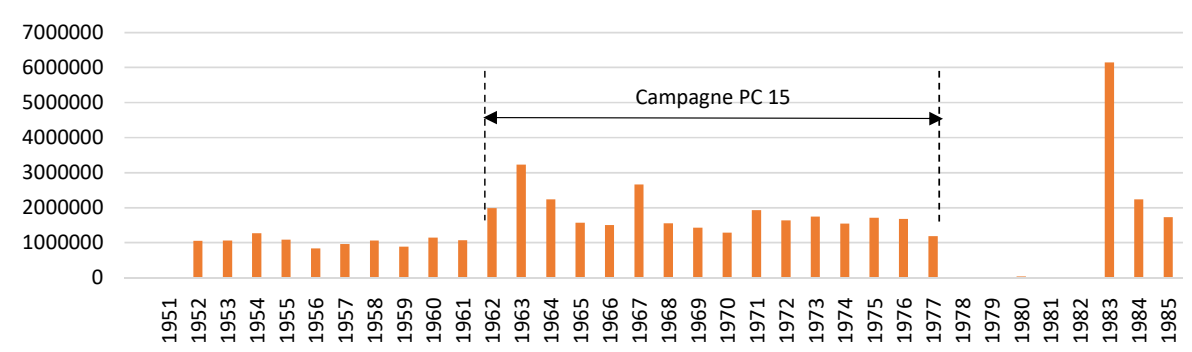


partir de 1966, seule la technique de production de virus sur culture cellulaire est utilisée. Or, deux nouvelles innovations majeures vont permettre d'améliorer l'efficacité de ce vaccin et donc l'impact des campagnes de vaccinations sur le terrain : il s'agit de la production de vaccins bivalents et de la production de vaccins thermostables.

En s'inspirant d'autres travaux conduits à l'étranger, des essais sont conduits à Farcha dès le début des années 1960 en vue de produire des vaccins polyvalents. En effet, en conditions tropicales où la prophylaxie est particulièrement difficile, ces vaccins mixtes sont susceptibles d'améliorer l'efficacité des programmes de lutte (Tacher, 2011). En 1965, un vaccin mixte antibovipestique-antipéripneumonique est mis au point par l'équipe de virologie du laboratoire (Provost et al., 1974). Ce vaccin Bisec, comme le Pestosec, utilise un virus bovipestique atténué produit sur culture cellulaire.

Au cours des années 1967 et 1968, 6232430 vaccinations sont réalisées au Tchad (IEMVT, 1968) dont 4209433 contre la peste bovine. Au premier trimestre de l'année 1969, seuls trois foyers de peste bovine sont signalés pour une dizaine de morts enregistrés. Fin 1970, plus aucun foyer n'est déclaré dans la zone d'intervention de la campagne conjointe (figure 2).

Un autre vaccin bivalent, le Neobisec, est proposé à partir de 1971. Il s'agit d'un vaccin utilisant une autre souche de Mycoplasma, l'agent pathogène responsable de la $\mathrm{PPCB}$. Elle provient de la souche T1 et non plus de la souche KH3J (OIE, 1972). A partir du début des années 1970, seuls les vaccins bivalents Bisec puis Neobisec sont produits de manière significative.

En 1971, un vaccin trivalent (charbon bactéridien, peste bovine et PPCB) est envisagé afin de profiter des avantages logistiques des vaccins polyvalents, en particulier pour les zones enclavées. Malheureusement, il s'avère que l'antigène charbonneux du vaccin mixte est détérioré par la solution de sulfate de magnésium utilisée pour améliorer la stabilité du vaccin. En conséquence, « le vaccin mixte décrit ne trouve pas son indication au Tchad, conclusion décevante pour le chercheur. Il n'en reste pas moins que le vaccin trivalent conserve son indication dans les Etats qui continuent à utiliser la réfrigération en glace fondante pour le transport des vaccins lyophilisés sur le terrain et surtout le rafraîchissement des diluants de reconstitution des vaccins lyophilisés » (Provost et al., 1974).

Parallèlement, dès 1965, les travaux du laboratoire sont orientés vers la mise au point d'un vaccin thermostable, notamment en utilisant du sulfate de magnésium lors de sa reconstitution à partir du lyophilisat, comme mentionné précédemment. Des techniques plus élaborées, basées sur la sélection de virus thermorésistants, aboutissent en 1972, après plusieurs études, à la production de virus thermorésistants. Ils sont utilisés pour la fabrication d'un vaccin qui résiste 14 jours à $45^{\circ} \mathrm{C}$ (Provost et Borredon, 1972). Cette nouvelle génération de vaccins va permettre aux services chargés de la prophylaxie de s'affranchir d'une partie des contraintes de la chaîne du froid.

\section{Poursuite des recherches et mise au point de méthodes de diagnostics}

A cette période, les recherches conduites au laboratoire accompagnent les développements des vaccins et la campagne de lutte PC 15. Elles portent notamment sur la caractérisation du virus pestique, sur la détermination de la durée de sa survie dans les carcasses d'animaux morts ou sur la mise au point de tests de diagnostics (IEMVT, 1966).

\section{Eradication provisoire de la peste bovine, puis fermeture de Farcha}

A partir de 1971, les foyers de peste bovine ont disparu du Tchad (figure 2). Cette éradication provisoire constitue un véritable succès de la campagne PC 15. Pendant les années 1970 et 1980, les campagnes de vaccinations et la collecte des données sont fortement perturbées par les difficultés budgétaires et par l'instabilité politique que connaît le pays, surtout à partir de 1978. Ces événements entraînent cette année-là la suspension des vaccinations puis l'arrêt de la production de vaccins (Vindrinet, 1991). De mai 1980 au 15 mars 1982, toutes les activités de production et de recherche sont ainsi suspendues (LRVZ, 1987).

Au Cameroun, pour faire face à cette incertitude dans la production de vaccins, le gouvernement décide en 1978, sous l'impulsion du Dr Abdoulaye Maikano, de construire son propre laboratoire de fabrication de vaccins à Garoua. C'est le Laboratoire national vétérinaire du Cameroun (Lanavet) qui entre en fonction au début des années 1980. La création de ce laboratoire a pour conséquence de priver celui de Farcha d'un de ses plus gros clients.

Les activités du Laboratoire de Farcha sont relancées en 1982 à la faveur de l'arrêt des troubles politico-militaires. La production des vaccins bactériens reprend progressivement en 1982-1983, puis dans les années 1983-1984 reprend celle des vaccins viraux.

\section{Réapparition de la peste bovine}

La peste bovine fait sa réapparition au Tchad en décembre 1982 à partir du Soudan. Elle envahit ensuite tout le territoire, d'abord le long de la piste à bétail dite « du $13^{\mathrm{e}}$ parallèle », puis vers le sud et le sudest en suivant les mouvements de transhumance (Cheneau, 1985). Fin 1982, 55 foyers de peste bovine sont dénombrés entre le Tchad et le nord du Nigeria. Entre janvier et juin 1983, ce sont 814 foyers qui sont dénombrés, causant la mort de 380298 bovins (Cheneau, 1985).

La réapparition de la peste bovine au Tchad intervient à un moment où les services de l'Etat sont désorganisés. Le Laboratoire de Farcha, producteur des vaccins, a rouvert, mais ses services ne sont pas tous opérationnels. Le Service de l'élevage, quant à lui, n'a pas de moyens adéquats pour lutter efficacement contre la peste bovine, véritable catastrophe nationale et toujours considérée par les éleveurs tchadiens comme un drame. Malgré ces contraintes, une campagne de vaccination d'urgence est lancée par le Tchad dès janvier 1983. Toutefois, pour répondre à cette crise le laboratoire ne dispose que d'un stock de 1000000 de doses de vaccin dans sa chambre froide, et le matériel frigorifique et les moyens de transport lui font cruellement défaut. « Le goulot d'étranglement pour le bon déroulement de cette campagne de lutte contre la peste bovine est constitué par le manque de vaccins. Les ruptures de stock sont fréquentes et l'approvisionnement difficile » (Mahamat Saleh, 1983a). Il faut donc commander des doses de vaccins auprès des laboratoires de Dakar au Sénégal et de Debre Zeit en Ethiopie, ainsi qu'en France, grâce à un financement de la coopération française (Mahamat Saleh, 1983b).

A partir de février 1983 l'effet positif de ces vaccinations se fait sentir. Le dernier foyer de peste bovine est notifié en 1984. Après 1985, presque tout le territoire national est exempt de foyers mais les vaccinations se poursuivent pour permettre le maintien d'un taux d'immunisation suffisant dans la population bovine. Une nouvelle période s'ouvre alors pour le Laboratoire de Farcha. Le nouveau contexte politique va conduire à un changement de structure.

\section{Redémarrage du Laboratoire de Farcha et sa contribution aux programmes PARC et PACE (1985-2007)}

Au sortir de la guerre civile et suite à l'accession au pouvoir de Hissène Habré, la présence au Tchad d'un laboratoire sous tutelle française est devenue anachronique. La cession du Laboratoire de Farcha aux autorités nationales intervient en 1985. Suite à cet accord, ses statuts sont modifiés et le centre quitte la tutelle de l'IEMVT (Gouvernement du Tchad, 1985). La direction du laboratoire est confiée à un chercheur tchadien, le Dr Idriss Alfaroukh. Cependant, la vocation du laboratoire reste la même, celle de l'amélioration de la santé et des productions animales aux fins du développement économique et social. 


\section{Organisation et fonctionnement}

Le laboratoire devient alors un établissement public à caractère industriel et commercial (EPIC) de droit tchadien doté de la personnalité civile et de l'autonomie financière (Gouvernement du Tchad, 1985). Il est rebaptisé Laboratoire de recherches vétérinaires et zootechniques de Farcha (LRVZ). Le conseil d'administration est présidé par le ministre en charge de l'Elevage et des Productions animales. Y siègent également le directeur de l'Elevage et des Industries, le directeur de l'Enseignement, de la Formation, de la Recherche vétérinaire et zootechnique, le chef de division recherche agronomique du ministère de l'Agriculture, des représentants des ministères des Finances, de l'Education, du Plan, un représentant de la présidence de la République et un représentant de l'IEMVT.

Le premier rapport d'activité du laboratoire publié après sa réouverture relate les activités des années 1986 et 1987. A cette période, le laboratoire bénéficie de l'appui de plusieurs partenaires. « Dans l'ensemble, les années 1986-1987 ont été des années test pour l'ensemble des activités du laboratoire qui ont été facilitées grâce au financement par le FAC [Fonds d'aide et de coopération], le FED et la FIS [Fondation internationale pour la science] pour l'équipement scientifique, de production et l'appui à la recherche ». Le nouvel organigramme crée un service d'épidémiologie pour renforcer la division de pathologie, et un service de parasitologie qui regroupe les anciens services d'helminthologie, d'entomologie et d'entomoprotozoologie (LRVZ, 1987).

L'arrivée de chercheurs tchadiens va alors permettre de prendre le relais des équipes françaises à la faveur de la poursuite des programmes de formation à l'étranger. De 1986 à 1989 le personnel tchadien compte environ 50 personnes, alors que l'effectif des agents français se maintient à un peu moins de 30 personnes, chercheurs et personnel technique compris. Cette transition se poursuit pendant les années 1990. Au début des années 2000, le personnel tchadien du laboratoire compte déjà 85 employés, dont 11 docteurs vétérinaires, 14 ingénieurs et cadres de niveau du diplôme d'études appliquées et du master, 3 administrateurs, 1 bibliothécaire, 22 cadres moyens, et 34 agents d'exécution. En ce qui concerne le personnel expatrié, le laboratoire n'est plus épaulé que par 10 experts de la coopération française (LRVZ, 1987 ; 1990 ; 1991 ; Servat et Tulasne, 2000).

\section{Production de vaccins}

En 1985, la production de vaccins contre la peste bovine et contre la PPCB est progressivement relancée en partenariat avec l'IEMVT qui vient d'être intégré au Centre de coopération internationale en recherche agronomique pour le développement (Cirad) (Lefèvre et Bréart, 1985). En vue de fournir des vaccins au programme PARC lancé en 1987, deux principaux vaccins sont produits à Farcha : le Pestosec et le Neobisec (tableau II).

Tableau II : Production de vaccins antibovipestiques au Laboratoire de recherches vétérinaires et zootechniques de Farcha (Tchad) de 1986 à 1990 /// Production of rinderpest vaccines at the Veterinary and Zootechnical Research Laboratory of Farcha (Chad) from 1986 to 1990

\begin{tabular}{lcr}
\hline Année & Neobisec & Pestosec \\
\hline 1986 & 4685900 & - \\
1987 & 2877500 & 2635000 \\
1988 & 3423800 & 387500 \\
1989 & 1399100 & 1790100 \\
1990 & 3069500 & 1097100 \\
\hline Source : LRVZ, 1990 & &
\end{tabular}

Les vaccins produits au Laboratoire de Farcha suivant les techniques développées par l'IEMVT sont de bonne qualité et répondent aux normes internationales. Toutefois, au niveau national il n'existe aucune structure indépendante pour contrôler la qualité des vaccins. Pour répondre à ce besoin de certification, le Centre panafricain des vaccins vétérinaires (Panvac) est créé en 1986 par l'Union africaine dans le cadre de la lutte contre la peste bovine, avec un centre à Dakar et un autre à Debré Zeit.

\section{Campagne panafricaine contre la peste bovine (1987-1998)}

Durant cette période, la lutte contre la peste bovine entre dans une nouvelle dynamique. L'objectif d'éradication de la maladie est décidé au niveau mondial. Le programme PARC est lancé en 1987 sous les auspices de l'Organisation des Nations unies pour l'alimentation et l'agriculture (FAO), de l'Office international des épizooties (OIE) et de l'OUA-BIRA. Trente-cinq pays africains sont impliqués dans cette campagne dont le financement est assuré par divers partenaires, dont la Communauté économique européenne qui y contribue pour 115 millions d'euros à travers les $6^{\mathrm{e}}$ et $7^{\mathrm{e}} \mathrm{FED}$.

$\mathrm{Au}$ Tchad, la stratégie consiste à vacciner tous les troupeaux entrant ou sortant du pays à l'aide du vaccin mixte peste-péripneumonie bovine. Le vaccin utilisé est le Neobisec fabriqué au Laboratoire de Farcha. Une fois l'opération effectuée, tous les animaux vaccinés doivent être obligatoirement identifiés pour permettre leur suivi. Des mesures de police sanitaire sont mises en place, notamment le contrôle des mouvements du bétail, des foires et marchés, et des pistes de transhumance.

En 1988 et 1989, la situation sanitaire est sous contrôle. Aucun foyer de peste bovine n'est signalé au cours de l'année 1989. Toutefois, la vaccination est maintenue, surtout à la frontière est du Tchad, la maladie continuant à sévir au Soudan. La vaccination se double d'une surveillance continue fondée sur des diagnostics et enquêtes épidémiologiques (LRVZ, 1990).

Les vaccinations dans le cadre du PARC sont lancées en même temps qu'un programme de libéralisation progressive de la profession vétérinaire. L'année 1993 marque au Tchad le début des activités des vétérinaires privés « mandataires » installés grâce à l'appui de l'Etat et de ses partenaires. En 1994, est mis en place un « cordon sanitaire» qui vise à empêcher la réémergence de la peste bovine à partir du Sud-Soudan vers les pays d'Afrique du centre et de l'ouest désormais indemnes. Pour le cheptel présent au sein du cordon sanitaire, la vaccination incombe aux agents de l'Etat : les services vétérinaires de l'Etat poursuivent donc leurs opérations de terrain. En revanche, pour les animaux situés en dehors du cordon sanitaire, la vaccination incombe aux vétérinaires privés (Bendali, 2001). La libéralisation des services et des produits vétérinaires conduit alors à une réorganisation du marché des vaccins qui aboutit à la perte progressive du monopole du Laboratoire de Farcha sur ces produits.

\section{Activités de recherche et de diagnostic}

La recherche et les travaux de diagnostic sur la peste bovine continuent d'être conduits à Farcha parallèlement à la production de vaccins. En 1986 le laboratoire lance par exemple une « Etude de l'état immunitaire du cheptel bovin vis-à-vis de la peste bovine » (Guillaud et al., 1989). Ces travaux sont poursuivis jusqu'en 1991 notamment grâce à un partenariat avec l'Agence internationale de l'énergie atomique, puis par d'autres enquêtes conduites en 1992-1993 par le LRVZ dans le cadre du PARC (Diguimbaye et al., 1993). Toutes ces études contribuent au pilotage des actions de lutte contre la maladie. Ainsi les travaux de Diguimbaye et al. (1993) soulignent « une nette amélioration du taux d'immunité chez les bovins vis-à-vis du virus bovipestique [...]. Les efforts entrepris en vue d'accroître le taux d'animaux immunisés doivent être maintenus ou renforcés selon les 
circonscriptions pour que le Tchad puisse assurer son rôle de barrière dans le cadre du PARC ».

En 1996 le Tchad envisage d'abandonner la vaccination contre la peste bovine. Toutefois, à cause de la présence du virus au Soudan et en Afrique de l'Est, une surveillance est maintenue pendant toute la fin du programme PARC jusqu'au début des années 2000. Le LRVZ participe alors activement à la poursuite des activités de sérosurveillance qui constituent une action phare du PARC.

Ces activités sont couplées aux activités de surveillance épidémiologique par la mise en place en 1995 du Réseau d'épidémiosurveillance des maladies animales au Tchad (Repimat). Ce réseau, animé par le service d'épidémiologie du LRVZ, est dédié au moment de sa création à la surveillance de cinq maladies autres que la peste bovine car cette dernière, considérée à cette période comme maladie rare, n'est pas incluse dans ce suivi national au moment du démarrage du réseau. Le Repimat couvre alors une dizaine de postes vétérinaires sur les 140 répartis dans les neuf circonscriptions d'élevage que compte le pays (Hendrikx et al., 1997). Cependant, en 1997, une mission d'évaluation externe du Repimat recommande que ce réseau puisse s'adapter pour « participer à l'épidémiovigilance de la peste bovine au Tchad » (Dufour et al., 1998). La peste bovine est alors intégrée à la liste des maladies surveillées par le Repimat qui bénéficie dès lors du financement du programme PARC et couvre l'ensemble des postes vétérinaires du pays.

Suite à l'arrêt du PARC en 1998, c'est le PACE qui va reprendre à son compte l'appui aux activités de sérosurveillance et d'épidémiosurveillance.

\section{Programme panafricain de contrôle des épizooties (1999-2007) et éradication définitive de la peste bovine}

Le PACE est lancé en 1999 pour pérenniser les acquis du programme PARC en établissant des réseaux de surveillance épidémiologique dans les pays africains. Coordonné par le Bureau interafricain des ressources animales de l'Union africaine (UA-IBAR), le PACE couvre 30 Etats du continent dont le Tchad. Ses activités sont élargies aux épizooties autres que la peste bovine, notamment à la PPR, à la PPCB et à la fièvre aphteuse (PACE, 2007).

Le PACE contribue, pour les programmes nationaux et régionaux de suivi de ces épizooties, à l'établissement d'une capacité de diagnostic différentiel de la peste bovine. Le programme se fonde sur la mise en place de véritables systèmes de surveillance qui intègrent a) des observations de terrain transmises en temps réel par les services vétérinaires (surveillance passive), b) des observations cliniques et des analyses en laboratoire permettant de confirmer les cas d'infection (surveillance active), et c) des enquêtes sérologiques (sérosurveillance) (PACE, 2007 ; Ouagal et al., 2010).

En raison de ses capacités en matière de production de vaccins et de diagnostic, le LRVZ constitue au Tchad le fer de lance du programme. Le Repimat voit ses capacités logistiques et matérielles considérablement améliorées par ce programme en vue de renforcer l'épidémiovigilance de la peste bovine (Ouagal et al., 2008). Une des innovations du PACE pour le suivi de la maladie au Tchad va alors consister à intégrer dans le système de surveillance une sérosurveillance de la faune sauvage sensible à la peste bovine. En effet, la sérosurveillance des bovins domestiques « ne fait pas de distinction entre l'infection par le virus sauvage et les anticorps vaccinaux, limitant ainsi la spécificité de cette méthode ». Les animaux sauvages représentent alors « une population sentinelle non vaccinée » (PACE, 2007).

A l'exception de certaines zones couvertes par les vétérinaires privés mandataires, la vaccination demeure majoritairement assurée par les agents étatiques. Les vaccins utilisés sont principalement ceux fournis par Farcha mais aussi dans certains cas le Bivax, vaccin mixte contre la peste bovine et la PPCB, produit au Cameroun par le Lanavet.

Dans les premières années du programme, la couverture vaccinale dans le cordon sanitaire reste en deçà de $30 \%$, et les sérologies concernant la faune sauvage sont négatives, ce qui prouve une absence d'infection récente de ces animaux. Par ailleurs, aucune suspicion de peste bovine n'est rapportée par le Repimat dont l'animation est transférée en 2001 à la Direction de l'élevage et des ressources animales (DERA) du ministère de l'Elevage afin de garantir une bonne implication des services vétérinaires. En conséquence, au Tchad tout au moins, le cordon est abandonné dès mars 2002 et la vaccination contre la peste bovine est suspendue (Bendali, 2003 ; PACE, 2007).

En 2002, le Tchad est déclaré « provisoirement indemne» de la maladie. Au cours des années suivantes, les suivis sérologiques et la surveillance épidémiologique se maintiennent. Grâce à ces garanties et à la disparition de tout foyer de peste bovine sur l'ensemble du territoire national, la demande du Tchad de déclaration d'éradication est approuvée par la commission scientifique de l'OIE en janvier 2006 (PACE, 2007). En 2007, c'est-à-dire à la clôture du programme, le Tchad et 11 autres pays sont reconnus indemnes de peste bovine par l'OIE.

\section{Période récente et perspectives}

Depuis l'arrêt du PACE en 2007, le Laboratoire de Farcha souffre de difficultés logistiques qui limitent sa capacité à rester un acteur majeur dans le domaine du diagnostic et de la production de vaccins. «Depuis sa création, le laboratoire produit des vaccins pour la protection du cheptel contre les différentes maladies. C'est grâce aux vaccins produits au Tchad que l'Afrique a été sauvée de la peste bovine et le Tchad a été déclaré indemne de cette maladie. Mais la production des vaccins a eu des difficultés à un certain moment et nous étions obligés d'en importer certains. Nous ne pouvions pas produire les vaccins au Tchad à cause de certains problèmes, entre autres le manque d'énergie. La production de vaccin nécessite l'utilisation de gros appareils [notamment un lyophilisateur et une chaîne du froid] qui consomment beaucoup d'énergie. Le générateur du laboratoire ne pouvant plus supporter les charges, cela a joué sur la qualité des vaccins et nous étions obligés d'en arrêter la production » (Anon., 2011).

En 2018, seuls trois vaccins bactériens y sont produits : l'Antravac contre le charbon bactéridien, le Symptovac contre le charbon symptomatique et le Pastovac contre la pasteurellose. Les installations des unités de production de vaccins viraux sont fermées faute de moyens et de personnel qualifié. Sur d'autres sujets, le laboratoire est resté actif, contribuant par exemple à développer des recherches originales en épidémiologie et santé animale, en pastoralisme ou sur les systèmes d'élevage et les filières (Colas, 1999 ; Jamin et al., 2003 ; Alfaroukh et al., 2011).

En 2012, pour appuyer sa relance, les autorités ont validé le changement de nom du laboratoire qui est devenu l'Institut de recherche en élevage pour le développement (IRED) (Gouvernement du Tchad, 2012). Une année plus tard, l'IRED participait activement à une réunion d'envergure internationale sur le pastoralisme en Afrique, confirmant sa position stratégique (SCSAO/AFD, 2013).

Tous ces efforts ont eu pour objet de préserver l'élevage tchadien qui demeure un secteur stratégique dans le développement économique du pays. En 2015, le recensement national du bétail (RGE, 2016) a évalué le nombre de ruminants à environ 93 millions de têtes. Un chiffre qui reste une estimation mais qui montre le chemin parcouru depuis le recensement du bétail de 1976 : il n'y avait alors que 8,6 millions de têtes. Pour ce qui est des bovins, le cheptel est passé de 3,3 à 25 millions de têtes entre 1976 et 2015 (RGE, 2016). Cette croissance particulièrement remarquable des effectifs a sans aucun doute bénéficié de manière déterminante des programmes de lutte contre la 
peste bovine auxquels le Laboratoire de Farcha a contribué. Le statut indemne du pays a aussi permis d'augmenter la production en lait et en viande et a ouvert des opportunités commerciales surtout en matière d'exportation de bétail sur pied vers ses voisins (Cameroun, Nigeria, Soudan et Libye) (Duteurtre et al., 2003 ; Koussou et al., 2012 ; PNDE, 2017).

\section{Conclusion}

Mis en place par les autorités coloniales françaises au début des années 1950, le Laboratoire de Farcha a été un centre de référence en matière de recherche, de diagnostic et de production de vaccins. Pendant les grandes campagnes panafricaines de lutte contre la peste bovine, il a joué un rôle central en élaborant plusieurs générations de vaccins et en contribuant à la mise au point d'outils de diagnostic et de surveillance. Grâce à l'appui de nombreux partenaires techniques et financiers, il a produit des millions de doses de vaccins jusqu'à l'éradication définitive de la peste bovine en 2007.

De sa création en 1949 jusqu'en 1961 (« temps des vaccins »), le laboratoire a été le lieu des premières recherches sur le virus et sur la prévalence de la maladie au Tchad, recherches qui ont abouti à la mise en place des premiers vaccins lyophilisés vivants produits localement. De 1962 jusqu'au milieu des années 1980 (« temps des campagnes »), le laboratoire a travaillé à la mise au point de vaccins mixtes et thermostables qui ont permis à la Campagne conjointe PC 15 d'aboutir à une éradication provisoire de la maladie au milieu des années 1970 Le laboratoire a ensuite connu une courte période de fermeture liée à l'instabilité politique dans le pays au début des années 1980. Après sa nationalisation en 1985 et jusqu'en 2007 (« temps de la surveillance »), le laboratoire (renommé LRVZ) a contribué aux divers projets et programmes nationaux et régionaux de lutte contre la peste bovine avec l'appui de nombreux partenaires européens et américains. Les programmes PARC et PACE, notamment, ont joué un rôle déterminant dans l'éradication de la maladie. Au cours de cette dernière période, l'appui du laboratoire aux activités de surveillance de la maladie a été essentiel.

Le laboratoire, devenu IRED, doit aujourd'hui répondre aux nouvelles réalités du secteur. L'éradication de la peste bovine a contribué à l'augmentation significative des effectifs bovins. De nombreux défis se posent encore à l'élevage tchadien, pilier de l'économie nationale, qui nécessitent de poursuivre les recherches dans de nombreux domaines. En raison des risques sanitaires qui restent élevés, des efforts sont nécessaires dans le domaine de la santé animale, en particulier pour lutter contre la PPR qui constitue un enjeu majeur au Sahel. L'élevage représente une ressource précieuse qui pourrait être mieux valorisée à travers la mise en place d'infrastructures de transformation et de commercialisation des produits animaux, comme des abattoirs, des boucheries modernes, des laiteries ou des tanneries. Les pratiques d'élevage et de gestion des ressources pastorales nécessitent, elles aussi, d'être appuyées pour favoriser la gestion concertée des ressources en vue de limiter les conflits, et la complémentarité entre agriculture et élevage, dans un contexte de changement climatique et de pression sur les ressources.

En fin de compte, l'histoire du Laboratoire de Farcha et des programmes d'éradication de la peste bovine illustre l'apport précieux de la recherche dans le développement. Alors qu'il vient de fêter ses 70 ans, cet institut devrait pouvoir continuer à contribuer à l'histoire des sciences et des techniques au Tchad, et à éclairer les stratégies de développement durable.

\section{Remerciements}

Les auteurs adressent leurs remerciements aux responsables de l'IRED, parmi lesquels son directeur général, le Dr Adoum Goudja, qui a contribué à orienter ces recherches. Les auteurs remercient aussi le Prof. Youssouf Mopate Logtene, directeur adjoint de l'IRED, pour sa lecture attentive du manuscrit et ses compléments précieux. Enfin, les auteurs tiennent à remercier le comité éditorial de la revue ainsi que les évaluateurs du manuscrit pour leurs remarques constructives et rigoureuses.

\section{Déclaration des contributions des auteurs}

Cette synthèse a fait en partie l'objet du master 2 de A.H. Deye (2018). AHD et MO ont participé à la conception et à la planification de l'étude. AHD a recueilli les données et rédigé une première version du manuscrit. GD, AHD et MO ont participé à la réécriture du manuscrit, à la collecte complémentaire d'archives et de références, à la confection des figures, et à la révision du manuscrit.

\section{Conflits d'intérêts}

Leétude a été réalisée sans conflit d'intérêts.

\section{REFERENCES}

Alfaroukh I., 1989. La recherche vétérinaire et zootechnique au Tchad: à la lumière des activités du Laboratoire de Farcha. Note de synthèse n³919/89. Laboratoire de Farcha, N’Djamena, Tchad

Alfaroukh I., Avella N., Grimaud P. (Eds), 2011. La politique sectorielle du pastoralisme au Tchad : quelles orientations? Coll. national, LRVZ, N'Djamena, Tchad, 1-3 mars 2011, 183 p.

Anon., 2011. Interview du directeur général du LRVZ Mahamat Hamid Mahamat. J. Notre Temps, 450: 3

Bendali F., 2001. Rapport de mission « Cordon Sanitaire », PACE. Cirad-EMVT, Montpellier, France, $18 \mathrm{p}$.

Bendali F., 2003. Le cordon sanitaire contre la peste bovine : bilan et perspectives. In: Actes Colloq. Savanes africaines : des espaces en mutation, des acteurs face à de nouveaux défis (Eds Jamin J.Y. et al.), Garoua, Cameroun, mai 2002. Cirad, Montpellier, France, 8 p.

Bidjeh K., Bornarel P., Imadine M., Lancelot R., 1995. Premier isolement au Tchad du virus de la PPR et reproduction expérimentale de la maladie. Rev. Elev. Med. Vet. Pays Trop., 48 (4): 295-300, doi: 10.19182/remvt.9427

Cheneau Y., 1985. Evolution de la peste bovine et stratégie de la campagne panafricaine. Rev. Sci. Tech. Off. Int. Epizoot., 4 (2): 403-414, doi: 10.20506/rst.4.2.196

Colas F. (Ed.), 1999. Actes des 3es journées agro-sylvo-pastorales, LRVZ, N'Djamena, Tchad 29 nov. - 3 déc., 319 p.

Curson H.H., 1919. Rinderpest in the New Langerberg Province of German East-Africa during 1917-1918. J. Comp. Path. Ther., 32: 197-210, doi: 10.1016/S0368-1742(19)80022-X

Daumal S., 1996. Autrefois l'élevage : L'institut d'élevage et de médecine vétérinaire des pays tropicaux : 1920-1993. Cirad, Montpellier, France, 152 p. (coll. Autrefois l'agronomie) 
Delate J.J., 1985. Note de synthèse sur les activités du Laboratoire de Farcha de sa création jusqu'en 1979. Cirad-lemvt, Maisons-Alfort, France, 37 p.

Deye A.H., 2018. Le Laboratoire de Recherche vétérinaire et zootechnique de Farcha et l'éradication de la peste bovine : 1949-2007. Mém. Master 2, Université de Nantes, France, 88 p.

Diguimbaye C., Kebkiba B., Bornarel P., 1993. La sérosurveillance sérologique des anticorps antivirus bovipestiques chez les bovins du Tchad. In: Proc. Sero-monitoring of rinderpest throughout Africa, Phase 2, Cairo, Egypt, 7-11 Nov. 1993. FAO, Rome, Italy, 147-148

Dufour B., Ouagal M., Idriss A., Maho A., Saboun M., Bidjeh K., Haggar A.I., et al., 1998. Evaluation du réseau d'épidémiosurveillance tchadien : Le REPIMAT. Epidémiol. Santé Anim., 33: 133-140

Duteurtre G., Koussou M.O., Essang T., Kadekoy-Tigague D., 2003 : « Le commerce de bétail dans les savanes d'Afrique centrale : réalités et perspectives ». In: Actes Colloq. Savanes africaines : des espaces en mutation, des acteurs face à de nouveaux défis (Eds Jamin J.Y. et al.), Garoua, Cameroun, mai 2002. Cirad, Montpellier, France, 7 p. https://agritrop.cirad.fr/527576/

Gallais J., 1979. La situation de l'élevage bovin et le problème des éleveurs en Afrique occidentale et centrale. Cah. Outremer, 126: 113-138, doi: 10.3406/caoum.1979.2897

Gouvernement du Tchad, 1960. Ordonnance nº 19 du 16 juil 1960 organisant la police sanitaire en matière de maladies contagieuses du bétail. N'Djamena, Tchad

Gouvernement du Tchad, 1962. Décret n 40/EL du 10 fév 1962 relatif au contrôle sanitaire de la circulation du bétail. N'Djamena, Tchad

Gouvernement du Tchad, 1985. Décret n 090/PR/MEHP/85 du 21 mars 1985, portant organisation et fonctionnement du LRVZ de Farcha. N'Djamena, Tchad

Gouvernement du Tchad, 2012. Ordonnance n 029/PR/2012 du 2 oct 2012 portant création en lieu et place du LRVZ, de l'IRED. N'Djamena, Tchad

Guillaud M., Fabre S.M., Imadiné M., Buron S., 1989. Evaluation de la protection sérologique contre la peste bovine du cheptel bovin tchadien. Rev. Elev. Med. Vet. Pays Trop., 42 (2): 163-167, doi: 10.19182/remvt.8821

Hendrikx P., Bidjeh K., Ganda K., Ouagal M., Haggar A.I., Saboun M., Maho A., et al., 1997. Le réseau d'épidémiosurveillance des maladies animales au Tchad, Rev. Sci. Tech. Off. Int. Epizoot., 16 (3): 759-769, doi: 10.20506/ rst.16.3.1071

IEMVT, 1958. Rapport d'activités 1958 du Laboratoire de Farcha. IEMVT / bibliothèque de IRED, Fort-Lamy, Tchad

IEMVT, 1960. Rapport d'activités 1960 du Laboratoire de Farcha. IEMVT / bibliothèque de IRED, Fort-Lamy, Tchad

IEMVT, 1962. Rapport d'activités 1962 du Laboratoire de Farcha. IEMVT / bibliothèque de IRED, Fort-Lamy, Tchad

IEMVT, 1963. Rapport d'activités 1963 du Laboratoire de Farcha. IEMVT / bibliothèque de IRED, Fort-Lamy, Tchad

IEMVT, 1966. Rapport d'activités 1966 du Laboratoire de Farcha. IEMVT / bibliothèque de IRED, Fort-Lamy, Tchad

IEMVT, 1968. Rapport d'activités 1968 du Laboratoire de Farcha. IEMVT / bibliothèque de IRED, Fort-Lamy, Tchad, 505 p.

Itard J., 2012. Un vétérinaire au Tchad en 1954-55 : Souvenirs. Bull. Soc. Fr. Hist. Méd. Sci. Vét., 12: 151-160

Jamin J.Y., Seiny Boukar L., Floret C. (Eds) 2003. Actes colloq. Savanes africaines : des espaces en mutation, des acteurs face à de nouveaux défis, Garoua, Cameroun, 27-31 mai 2002. Cirad, Montpellier, France

Koussou M.O., Grimaud P., Aubague S., 2012. Les filières d'exportation du bétail sur pied au Tchad. Bull. Anim. Health Prod. Afr., 60 (4) : 539-548

Lefèvre P.C., Bréard A., 1985. Relance de la production des vaccins anti-peste bovine et antipéripneumonie contagieuse au Laboratoire de Farcha (Tchad). Rapport de mission. Cirad-lemvt, Maisons-Alfort, France, 23 p.

Leplae E., Carlier F., Van Saeghem R., Chiwy H., 1925. Notes relatives à la lutte contre la peste bovine. G. Wagemans, Bruxelles, Belgique, $39 \mathrm{p}$.

Libeau G., Lancelot R., Martinez P., 2011. La contribution du Cirad à l'éradication de la peste bovine. EMPRES Bull. Mal. Anim. Transfront. 38: 54-55

LRVZ, 1987. Rapport d'activité 1986. Laboratoire de recherche vétérinaire et zootechnique de Farcha, N'djamena, Tchad (consulté à la bibliothèque de I'IRED)
LRVZ, 1990. Rapport d'activité 1989-1990. Laboratoire de recherche vétérinaire et zootechnique de Farcha, Tchad (consulté à la bibliothèque de I'IRED)

LRVZ, 1991. Plan directeur. Laboratoire de recherche vétérinaire et zootechnique de Farcha N'Djamena, Tchad (consulté à la bibliothèque de I'IRED)

Mahamat Saleh A., 1983a. Rapport sur la réapparition de la peste bovine au Tchad du 18 janvier 1983. Bureau de coordination de la campagne d'urgence de lutte contre la peste bovine, Laboratoire de Farcha, Min. de I'Elevage, N'Djamena, Tchad, $5 \mathrm{p}$.

Mahamat Saleh A., 1983b. Troisième rapport de la campagne d'urgence contre la peste bovine du 22 février 1983. Bureau de coordination de la campagne d'urgence de lutte contre la peste bovine. Minist. Elevage, Laboratoire de Farcha, N'Djamena, Tchad

Mornet P., Orue J., Labouche C., Majnguy P., 1953. Les virus-vaccins contre la peste bovine : Le virus bovipestique lapinisé. Rev. Elev. Med. Vet. Pays Trop., 6 (3): 125-166, doi: 10.19182/remvt.6917

OIE, 1972. Rapport 2e conf. Commission régionale de l'OIE pour l'Afrique, Khartoum, Soudan, 7-10 déc. 1971. Bull. Off. Int. Epizoot., 77 (1-2): 3-4

OIE, 2013. Fiches d'information générale sur les maladies - Rinderpest. www. oie.int/fileadmin/Home/eng/Animal_Health_in_the_World/docs/pdf/Dise ase_cards/RINDERPEST.pdf

Ouagal M., Hendrikx P., Berkvens D., Ncharé A., Cissé B., Akpeli P.Y., Sory K. et al., 2008. Les réseaux d'épidémiosurveillance des maladies animales en Afrique francophone de l'Ouest et du Centre. Rev. Sci. Tech. Off. Int. Epizoot., 27 (3): 689-702, doi: 10.20506/rst.27.3.1828

Ouagal M., Hendrikx P., Saegerman C., Berkvens D., 2010. Comparison between active and passive surveillance within the network of epidemiological surveillance of animal diseases in Chad. Acta Tropica, 116 (2): 147 151, doi: 10.1016/j.actatropica.2010.07.004

PACE, 2007. Programme pan-africain de contrôle des épizooties, vol. 1 Rapport descriptif. www.au-ibar.org/component/jdownloads/finish/29-pace/675-pace-final-report-vol-1-narrative-report

PNDE, 2017. Plan national de développement de l'élevage. Ministère de l'Elevage, FAO, N'Djamena, Tchad, $103 p$

Provost A., 1961. Note sur la possibilité d'emploi du vaccin antibovipestique de culture tissulaire pour la protection des zébus vivant en zone d'endémicité trypanosomienne. Rev. Elev. Med. Vet. Pays Trop., 14 (4): 369-373, doi: 10.19182/remvt.7085

Provost A., Villemot J.M., Queval R., 1961. Emploi du vaccin avianisé souche B.A. contre la peste bovine en Afrique Centrale. Rev. Elev. Med. Vet. Pays Trop., 14 (4): 375-383, doi : 10.19182/remvt.7086

Provost A., Borredon C., 1972. Un vaccin mixte antibovipestique-antipéripneumonique lyophilisé utilisable, sur le terrain, sans réfrigération : 1 . Sélection de virions bovipestiques à inactivation thermique retardée. Rev Elev. Med. Vet. Pays Trop., 25 (4): 507-520, doi: 10.19182/remvt.7772

Provost A., Borredon C., Bocquet P., 1974. Un vaccin mixte trivalent contre la peste bovine, la péripneumonie et le charbon bactéridien. Rev. Elev. Med. Vet. Pays Trop., 27 (4): 385-395, doi: 10.19182/remvt.7935

RGE, 2016. Recensement général de l'élevage, vol.

II : Principaux résultats définitifs. Ministère de l'Elevage et des Productions animales, N'Djamena, Tchad, $78 \mathrm{p}$.

Sacquet E., Troquereau P., 1952. Essai de vaccination contre la peste bovine au moyen du virus capri-pestique dans le Nord-Est du Tchad. Rev. Elev. Med. Vet. Pays Trop., 5 (2): 45-50, doi: 10.19182/remvt.6901

SCSAO- AFD, 2013. Elevage pastoral : Une contribution durable au développement et à la sécurité des espaces saharo-sahéliens. N’Djamena, Tchad $162 \mathrm{p}$.

Servat D., Tuslasne J.J., 2000. Réhabilitation des infrastructures des laboratoires de diagnostic et de recherches du Laboratoire de recherches vétérinaires et zootechniques de Farcha, N'Djamena, Tchad. Cirad-EMVT, Montpellier, France, $50 \mathrm{p}$.

Sunseri T., 2018. The African rinderpest panzootic, 1888-1897. Oxford University Press, London, UK, doi: 10.1093/acrefore/9780190277734.013.375

Tacher G., 2011. Campagnes de vaccination bovine au Tchad : souvenir des années 1960. Bull. Soc. Fr. Hist. Med. Sci. Vet., 11: 107-115

Vindrinet R., 1991. Note sur quelques enseignements de la lutte contre la peste bovine au Tchad depuis 1935. Rev. Elev. Med. Vet. Pays Trop., 44 (1): 38-41, doi: 10.19182/remvt.9213 


\section{Summary}

Deye A.H., Duteurtre G., Ouagal M. Farcha Laboratory and rinderpest eradication programs in Chad from 1949 to 2007: a review

This work reviews the role of the Institut de recherche en élevage pour le développement (IRED), formerly Farcha Laboratory, in the control of rinderpest in Chad. Created in 1949 by colonial authorities, this laboratory located in N'Djamena has been playing a decisive role in rinderpest research in Central Africa since its creation. During the first period, or "Vaccines' Period" (1953-1961), the laboratory's work led to the production of several generations of vaccines. In the second period, or "Campaigns' Period" (1962-1985), these vaccines were used on a large scale for disease eradication programs. The cell culture vaccines produced in Farcha were used in particular in the campaign launched by the Organization of African Unity (1962-1976) under the name of Joint Program No. 15. This program led to the temporary eradication of rinderpest in Chad. Unfortunately, the persistence of rinderpest outbreaks in several regions of Africa and the cessation of vaccination campaigns in Chad in the late 1970 s led to its return in 1982. After relaunching vaccine production in 1983 and nationalizing the laboratory in 1985, Farcha kept playing a part in rinderpest control. During the third period, or "Surveillance Period" (1986-2007), the laboratory actively contributed to the Pan-African Rinderpest Campaign (PARC), then to the Pan-African Program for the Control of Epizootics (PACE), notably through epidemio- and sero-surveillance activities. These programs led to the definitive eradication of the disease in the region. Since 2007, Chad has been declared rinderpest-free, which has contributed to a rapid increase in the number of cattle in the country and has opened up trade opportunities, especially in the export of live cattle to neighboring countries.

Keywords: cattle, rinderpest, vaccine, livestock-raising, veterinary laboratories, Chad

\section{Resumen}

Deye A.H., Duteurtre G., Ouagal M. El Laboratorio de Farcha y los programas de erradicación de la peste bovina en Chad de 1949 a 2007: una síntesis

Este trabajo de síntesis presenta el papel del Instituto de investigación de crianza para el desarrollo (IRED), antiguamente Laboratorio de Farcha, en la lucha contra la peste bovina en Chad. Creado en 1949 por las autoridades coloniales, este laboratorio implantado en Yamena jugó desde su creación un papel determinante en las investigaciones sobre la peste bovina en África central. En el primer periodo, o "tiempo de vacunas" (1953-1961), los trabajos del laboratorio conducen principalmente a la fabricación de varias generaciones de vacunas. En el segundo periodo, o "tiempo de campañas" (1962-1985), estas vacunes son utilizadas a gran escala para programas de erradicación de la enfermedad. Las vacunas en cultivo celular producidas en Farcha son en particular utilizadas durante la campaña lanzada por la Organización de la Unidad africana (1962-1976) bajo el nombre de Programa conjunto $n^{\circ} 15$. Este programa llevó a la erradicación temporal de la peste bovina en Chad. Desgraciadamente la persistencia de focos de la enfermedad en varias zonas de África y la suspensión de las campañas de vacunación en Chad a fines de los años 1970 condujeron a un retorno a partir de 1982. Después del reinicio de la producción de vacunas en 1983, luego de la nacionalización del laboratorio en 1985, Farcha se mantiene activo en la lucha contra la peste bovina. En el curso del tercer periodo, o "campaña de vigilancia" (1986-2007), el laboratorio contribuye activamente a la Campaña panafricana contra la peste bovina (PARC), luego al Programa panafricano de control de epizootias (PACE), principalmente mediante actividades de vigilancia epidemiológica y de vigilancia serológica. Estos programas conducen a la erradicación definitiva de la enfermedad en la región. Desde 2007, Chad ha sido declarado indemne a la PB, lo que ha contribuido al aumento rápido de los efectivos bovinos en el país y le ha abierto oportunidades comerciales, sobre todo en materia de exportación de ganado en pie a sus vecinos.

Palabras clave: ganado bovino, peste bovina, vacuna, ganadería, laboratorios veterinarios, Chad 